\title{
CYCLIC OLIGOMERS IN THE CATIONIC POLYMERIZATION OF HETEROCYCLES
}

\author{
E. J. Goethals \\ Institute of Organic Chemistry, Rijksuniversiteit Gent, Krijgslaan 271, 9000 Gent, Belgium
}

\begin{abstract}
The cationic polymerization of heterocyclic monomers may lead to polymers containing substantial, yet variable amounts of cyclic oligomers. This review gives a survey of the systems where such oligomers have been found. Oligomer formation is generally observed in the polymerization of oxiranes and thiiranes. The most frequently observed oligomers are the cyclic dimers and cyclic tetramers but other structures are also possible. It is not clear at the present which factors determine the structure of the oligomer.

During the polymerization of aziridines also, cyclic oligomers may be formed. With these monomers, the nature of the catalyst, solvent and temperature are important factors. Of the four-membered heterocyclics, only oxetanes have been found to produce cyclic oligomers.

From studies with oxiranes, thiiranes and some aziridines it follows that the oligomers are produced by degradation of first formed polymer and not directly from the monomer. The active species for degradation are the corresponding onium ions. From a thermodynamic point of view it is expected that polymers obtained from three-membered ring heterocycles degrade to form oligomers but it is not clear why in some cases dimers, and in other cases higher oligomers are formed.
\end{abstract}

\section{INTRODUCTION}

According to a number of reports of the last two decades it becomes now more and more evident that cationic polymerization of heterocyclic monomers may lead to polymers containing substantial, yet variable amounts of cyclic oligomers. In many cases the oligomers are the main reaction products. The aim of this article is to give a review of the different systems where such reactions have been observed, including a number of unpublished results from the author's laboratory, to discuss some of the proposed mechanisms for oligomer formation and finally to try to derive some general rules which govern this kind of reaction.

\section{SURVEY OF THE LITERATURE}

\section{Oxiranes}

The best known example of an oligomer-forming monomer is ethylene oxide. This monomer has been studied extensively by Eastham and coworkers. ${ }^{1-3}$ When ethylene oxide is polymerized by boron trifluoride in molecular weight of about 700 . Monomer continues to disappear more or less indefinitely, but this is continues to disappear more or less indefinitely, but this is due almost entirely to the formation not of new polymer but of dioxane. ${ }^{2}$ It is believed that the dioxane is formed by degradation of the polymer via oxonium salts. ${ }^{3}$ This was deduced from the observation that, if high molecular weight polyglycols are introduced to the reaction mixture, their molecular weight is reduced until the average molecular weight is again about 700. Triethyl oxonium tetrafluoroborate degrades polyethyleneglycol to dioxane and attempts to polymerize ethylene oxide with this oxonium salt failed, the only reaction product being dioxane. Apparently, dioxane formation via oxonium salts is favored over with propagation.

The polymerization of ethylene oxide by stannic chloride leads to polymers with a molecular weight up to $20,000 .{ }^{1}$ Chain growth and dioxane formation seem to be parallel with each consuming about one half of the monomer. In a recent patent it is claimed that ethylene oxide leads to a mixture of cyclic oligomers of D.P. 3, 4, 5, $6,7,8$ and 9 (7:7:4:6:6:2:1) when treated with fluorine-containing catalysts such as antimony pentafluoride. ${ }^{4}$
A number of other epoxides have been found to produce cyclic oligomers. Propylene oxide, when treated with triethyl oxonium tetrafluoroborate or boron trifluoride, produces a mixture of cyclic oligomers (in yields up to $60 \%$ ), the most important one being the tetramer. ${ }^{5,6}$

Because of the occurrence of head-to-tail and head-tohead structures and of cis-trans isomerism, the cyclic tetramer can occur as 23 different geometrical isomers. By a combination of gas chromatography, $\mathrm{H}^{1}-\mathrm{NMR}$ - and mass spectroscopy, Katnik and Schaefer were able to observe 22 out of the 23 isomers and to characterize the majority of them. ${ }^{5}$ When propylene oxide is polymerized by trimethyl aluminum at $0^{\circ} \mathrm{C}$, cyclic tetramer together with some cyclic dimer and trimer is formed in the first stages of the polymerization. ${ }^{7}$ Polymerization of 1,2butylene oxide with triethyl oxonium tetrafluoroborate or boron trifluoride leads to a mixture of polymer, dimer, tetramer and larger rings. ${ }^{6}$ The tetramer is the most important reaction product.

The formation of small amounts of 2,5-diphenyl dioxane from styrene oxide has been reported by Colclough and coworkers, ${ }^{8}$ and by Pasika. ${ }^{9}$ The first authors used Friedel-Crafts catalysts and the maximal yield of dimer was $10 \%$. (The same catalysts gave no oligomers with ethylene oxide or propylene oxide.) The second author obtained the dimer in 2-3\% yield when styrene oxide was polymerized with triphenylmethyl hexachloroantimonate. Pasika's dimer has a m.p. of $171-172^{\circ} \mathrm{C}$ and the author presents good evidence that it is the trans-isomer. Colclough and coworkers do not discuss the geometry of their dimer and report a sharp m.p. of $152^{\circ} \mathrm{C}$. Possibly the lower melting compound is the cis-isomer or a mixture of cis- and trans-isomers.

Trans-2,5-diphenyl dioxane has also been isolated by Kondo and Blanchard during the cationic copolymerization of styrene oxide with propylene oxide. ${ }^{9}$ These authors report a m.p. of $177^{\circ} \mathrm{C}$.

In a review article, Eastham reports that treatment of isobutylene oxide with boron trifluoride leads to dimer without any polymer ${ }^{11}$ but the reaction conditions were not mentioned. On the other hand, Vandenberg reported that the polymerization of the same monomer gave $60 \%$ of polymer plus some impurities, which were supposed 
to be cyclic oligomers. ${ }^{12}$ The formation of cyclic oligomers from epichlorohydrin has been reported in several papers. ${ }^{6,13-15}$ Weissermel and Nölken reported that epichlorohydrin reacts with triethyl aluminum to form the cyclic dimer. ${ }^{13}$ Kern, $^{6}$ and Entelis and coworkers ${ }^{14,15}$ found tetramer and small amounts of larger rings when the monomer was treated with boron trifluoride or triethyl oxonium tetrafluoroborate. With the first initiator, the ratio of tetramer to polymer was greater in the early stages of the reaction than after longer reaction periods. ${ }^{14}$ From this observation it was concluded that tetramer and polymer were formed by two independent reaction paths. The ratio of oligomers to polymer increased with temperature. $^{15}$

The nitrate of glycidyl epoxide forms a mixture of polymer and of cyclic tetramer. The amount of tetramer is smaller than in the cases of epichlorohydrin or propylene oxide, which was attributed to the higher steric hindrance in the nitrate. ${ }^{14}$

\section{Oxetanes}

When treated with typical cationic initiators, oxetane and 3,3-dimethyl oxetane form mixtures of polymer and cyclic tetramer (16-membered rings). ${ }^{16}$ Increase of the of tetrahydrofuran has not been observed. ${ }^{18}$ In the case of 1,3-dioxolane, small amounts of oligomers going from dimer to nonomer have been isolated. ${ }^{19}$ Under the influence of boron trifluoride etherate in methylene chloride at $35^{\circ} \mathrm{C}$, small amounts of 1,3,5-trioxepane are formed..$^{20}$ This indicates the existence of a "back-biting" reaction in the polymerization of dioxolane.

Okamura and coworkers made an extensive study of the polymerization of trioxane under the influence of boron trifluoride or its complexes. ${ }^{21}$ During the polymerization, an eight-membered ring, tetroxane, is formed rapidly, but this compound takes part in the polyoxymethylene formation. Thus an equilibrium concentration of tetroxane results when the rate of formation becomes equal to the rate of consumption. ${ }^{22}$ Minor amounts of a ten-membered ring, pentoxane, are also formed. $^{23}$ The authors conclude that tetroxane and pentoxane are formed by a "back-biting" mechanism. The occurrence of a "back-biting" reaction is further indicated by the observation that in copolymerizations of trioxane or tetroxane with vinyl monomers, various 1,3-dioxane derivatives are formed. ${ }^{24}$ With styrene for example, the derivative was 4-phenyl-1,3-dioxane, the formation of which was explained as follows (Scheme 1):<smiles>COCOCOCCC(C)C</smiles>

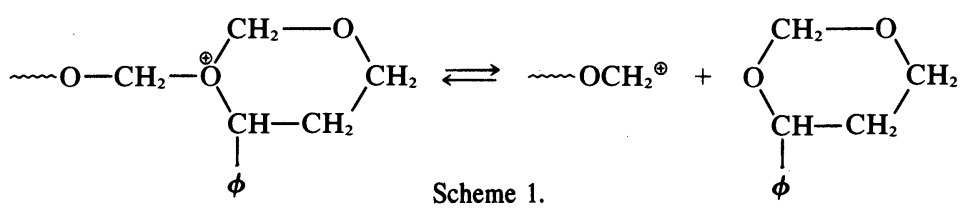

temperature increases the proportion of tetramer in the reaction products. Oxetane for example gives $4 \%$ of tetramer at $-80^{\circ} \mathrm{C}$ but at $50^{\circ} \mathrm{C} 66 \%$ of the reaction products were tetramer (total tetramer yield: $42 \%$ ). This is not an equilibrium effect, for the final conversion of monomer to polymer and tetramer obtained by heating the product of a polymerization carried out at $-80^{\circ} \mathrm{C}$ without removing the catalyst, was almost the same as that obtained at $-80^{\circ} \mathrm{C}$. The mechanism of tetramer formation proposed by Rose is, that after 4 propagation steps, the growing species is attacked by the hydroxyl function situated at the beginning of the chain, forming tetramer and initiator:

$$
\mathrm{HO}\left(\mathrm{CH}_{2}\right)_{3}+\mathrm{O}\left(\mathrm{CH}_{2}\right)_{3} \mathrm{t}_{2} \underset{\mathrm{BF}_{3} \mathrm{OH}^{\ominus}}{\stackrel{\oplus}{\mathrm{O}}\left(\mathrm{CH}_{2}\right)_{3}} \rightarrow\left[\mathrm{H}\left(\mathrm{CH}_{2}\right)_{3} \mathrm{~J}_{4}\right]+\mathrm{H}_{2} \mathrm{OBF}_{3}
$$

However, when strong alkylating agents such as triethyloxonium salts are used as the initiator, cyclic oligomer is also formed. Since in this case no terminal hydroxyl groups are formed, the formation of the tetramer must also be possible by another reaction mechanism.

From the polymerization products of 3,3bis(chloromethyl) oxetane with triethyl aluminum a small amount of cyclic trimer has been isolated. ${ }^{17}$

\section{Five-, six- and seven-membered cyclic ethers}

The formation of cyclic oligomers in the polymerization
Plesch and Westermann found that under the influence of perchloric acid, 1,3-dioxane forms a cyclic dimer which was formed only when conditions favoured crystallisation from the reaction mixture. ${ }^{25}$

The same authors report that during the polymerization of 1,3-dioxepane with perchloric acid, appreciable quantities of dimer are produced. ${ }^{25}$ Yamashita, who studied the kinetics of the same polymerization, reports that the molecular weight of the polymer increases with conversion until a maximum value is attained and then decreases drastically at higher conversions. ${ }^{26}$ Possibly this phenomenon is to be attributed to a degradation of the polymer to form the dimer or higher oligomers.

\section{Thiiranes}

Seven substituted thiiranes have been investigated in the authors' laboratory. ${ }^{27-29}$ All monomers behaved in a similar way: a rapid polymerization was followed by degradation to cyclic oligomers. The speed of the degradation and the structure of the oligomers varied with the monomer. Propylene sulfide and 1,2-butylene sulfide degraded slowly to form mainly tetramers. No dimers were formed. Styrene sulfide, cyclohexene sulfide and isobutylene sulfide formed dimers. Poly(trans-2,3-butylene sulfide) rapidly degraded to form equimolar amounts of 3,5,6,7-tetramethyl-1,2,5-trithiacycloheptane and transbutene. Trans-2,3-butylene sulfide has a threo configuration (RR or SS). If the polymerization occurs via an $\mathrm{S}_{\mathrm{N}} 2$ attack of the sulfide function of a monomer molecule on 
the $\alpha$-carbon of a three-membered ring sulfonium salt, one of the asymmetric carbons will undergo an inversion of configuration leading to a polymer in which the units have erythro configurations (RS or SR, meso form). Considering the fact that in the transition state of elimination reactions, the two leaving groups generally must occur in an anti-position to each other, the following mechanism is in agreement with the observation that the degradation leads to trans-butene exclusively (Scheme 2):
The last reaction however (formation of dimethyl sulfate from the methylsulfonium salt) is highly improbable. The cationic polymerization of styrene sulfide has been reinvestigated by Van Craeynest. ${ }^{29}$ With triethyl oxonium tetrafluoroborate as initiator a rapid and quantitative polymerization was observed, followed by a slower but complete degradation of the polymer to a mixture of isomeric diphenyl-1,4-dithianes. Since the $\mathrm{BF}_{4}{ }^{\ominus}$ counter ion is not capable for forming a covalent bond, a simple

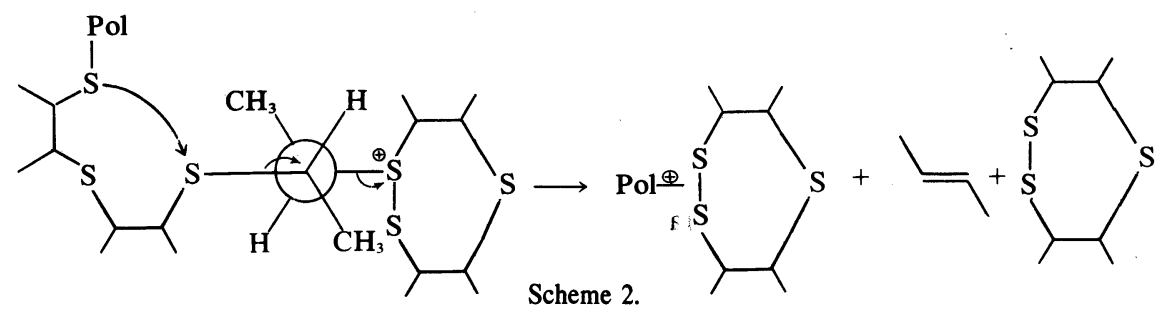

The polymer of cis-2,3-butylene sulfide forms a mixture tetramer, the trithiacycloheptane derivative and cisbutene.

The assumption that oligomers are formed by degradation of the polymer is confirmed by the observation that high molecular weight poly(propylene sulfide) obtained by anionic or ionic coordinative polymerization, is also degraded when treated with a catalytic amount of triethyl oxonium tetrafluoroborate. ${ }^{25}$ Since the reaction of an oxonium salt with a sulfide leads to a sulfonium salt, it is very likely that the degradation reactions are "back-biting" reactions occuring via sulfonium salts.

In all cases addition of new monomer to a degraded reaction mixture resulted in an instantaneous start of polymerization of the freshly added monomer, followed by degradation. When the reaction mixture was analysed by gel-permeation chromatography using refractive index and conductivity of the eluents as detection systems, it was observed that during the degradation process the charges were located on the polymer and not on the oligomer, which is in agreement with the "back-biting" mechanism. The degradations can be stopped at any moment by adding a small amount of tetrahydrothiophen to the reaction mixture. This sulfide is known to react rapidly with sulfonium salts to form a S-alkyl tetramethylenesulfonium salt. ${ }^{30}$ The resulting reaction mixture is then incapable of initiating polymerization of freshly added monomer.

The formation of a cyclic dimer during the polymerization of styrene sulfide had been reported by Noshay and Price. ${ }^{31}$ These authors reported the formation of 2,5diphenyl-1,4-dithiane in $15 \%$ yield when the polymerization was initiated with dimethyl sulfate at room temperature. The following mechanism was proposed (Scheme 3): "back-biting" reaction seems the plausible mechanism for the dimer formation. It was found that with dimethyl sulfate also, a mixture of isomers was obtained. However, 2,5-diphenyl-1,4-dithiane was the only isomer which crystallized from the solution in pure form.

\section{Aziridines}

Dick has shown that a number of 1-alkylaziridines are converted into the corresponding 1,4-dialkylpiperazines in yields as high as $95 \%$, when treated with hydrohalic acids in acetone or methyl ethyl ketone. ${ }^{32,33}$ Perchloric acid and $p$-toluenesulfonic acid resulted in the formation of poly(1-alkylaziridines) rather than piperazines. The major products formed in a water solvent were polymers with 1,4-dialkylpiperazines being formed in maximum yields of $27 \%$ in the case of hydroiodic acid. The mechanism proposed by Dick is, that the piperazine derivatives are formed via a dimer in which the halogen atom of the initiating acid has formed a covalent bond with a carbon atom. This covalent bond would not be formed with the perchloric acid or with $p$-toluene sulfonic acid, resulting in production of polymer exclusively.

When instead of the acids, alkyl halides or methyl $p$ toluenesulfonate were used as the initiator, the dimerization reaction stopped at the $N$-alkyl piperazinium salt stage. ${ }^{32}$ Here also, dimer formation was favored in acetone while solvents of high polarity and solvating power tended to favor polymer formation.

Dimer formation from $N$-alkylaziridines need not necessarily occur via a covalent bond formation with the counter ion. Bruggeman found that a number of 1-substituted aziridines form a mixture of polymers and the corresponding piperazine derivatives when treated with triethyl oxonium tetrafluoroborate in methylene<smiles>C[S@@]1(CS(=O)(=O)O)CC1OC1CC1C1CS1</smiles>

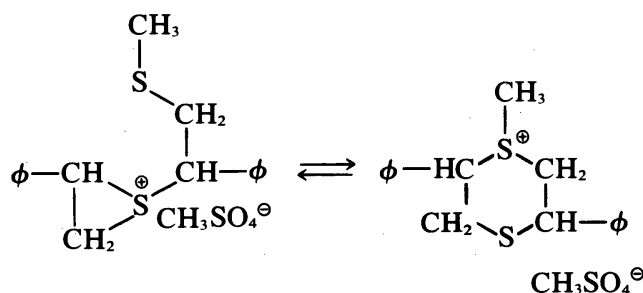<smiles>CC(C)(C)[O+]=O</smiles> 


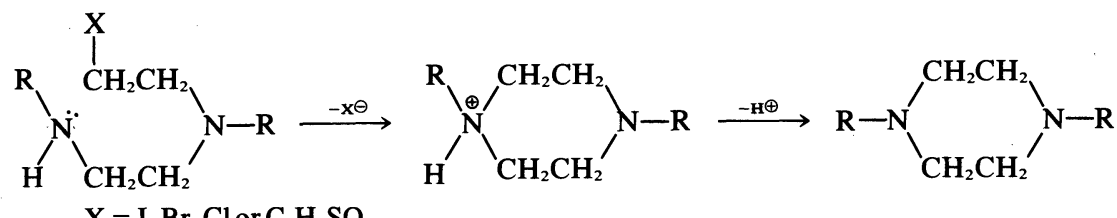

Scheme 4.

chloride. $^{35}$ The first reaction product is polymer which degrades more or less slowly to form the cyclic oligomer. Since the $\mathrm{BF}_{4}^{-}$ion is not capable of forming a covalent bond, a degradation of polymer involving quaternary ammonium salts is the most probable mechanism in this case (Scheme 4).

Whether an aziridine forms a polymer, an oligomer or a mixture of the two reaction products depends on small changes in monomer structure, the initiator used, and on the reaction conditions. 1-Benzylaziridine for example, is reported to form a cyclic tetramer in nearly quantitative yields with $p$-toluenesulfonic acid in boiling ethanol. ${ }^{34}$ The same monomer leads to a polymer which partially degrades to cyclic dimer when treated with triethyl oxonium salts in methylene chloride at $20^{\circ} \mathrm{C} .{ }^{35} 1-B e n z y l-2-$ methylaziridine does not form cyclic oligomers with triethyl oxonium tetrafluoroborate ${ }^{35}$ but 1-benzyl-2(R)ethylaziridine forms a mixture of polymer and tetramer in a ratio depending on the temperature, when treated with boron trifluoride etherate. ${ }^{36}$ 1Ethylaziridine, $^{34}$ 1-butylaziridine, ${ }^{34}$ 1-allylaziridine ${ }^{34}$ and 1-(2-phenylethyl)aziridine $e^{34,35}$ form dimers. However, 1(2-hydroxyethyl)aziridine does not form the corresponding piperazine ${ }^{34}$. while 1-(2-cyanoethyl)aziridine forms a mixture of polymer and tetramer. ${ }^{35} 1$-Propylaziridine, 1- $i$ butylaziridine and 1-phenylaziridine do not form oligomers when treated with triethyl oxonium tetrafluoroborate in methylene chloride. ${ }^{37}$

\section{DISCUSSION}

\section{General remarks}

Many of the cyclic oligomers reported in the literature have been discovered by chance. For example the oligomer may have formed a crystalline precipitate or been present in such great quantities that it could not be overlooked. Only in the last years, thanks to the introduction of gel permeation chromatography techniques, has it been possible to analyze more accurately polymer mixtures for the presence of, oligomers. Also, except in a few cases, it is not known whether the amount of oligomer reported in a paper was invariably the same or if it was a fortuitous amount typical for a particular experiment. A striking example is that of the 2,3-butene episulfides. Under the influence of triethyl oxonium tetrafluoroborate, reaction at $0^{\circ} \mathrm{C}$ for a relatively short reaction time yields polymer in quantitative yields. However, after a few hours the polymer is already partially degraded and if the experiments are carried out at room temperature using "normal" polymerization times only cyclic oligomers are obtained. ${ }^{30}$ So the question remains open as to the amount of oligomers formed with monomers such as styrene oxide, propylene oxide etc. under other reaction conditions than those described by the respective authors. It is also very probable that several monomers, which have not been reported to form oligomers, in fact do form oligomers but that these have not been observed because they either coprecipitated with the polymer or were eliminated during the purification of the polymer.

\section{Reaction mechanisms}

A number of authors propose mechanisms for oligomer formation. The mechanisms can be divided into two substantially different groups: (a) oligomer formation is a side reaction of the polymerization, which means that oligomer is formed directly from monomer; (b) oligomers are formed by degradation of polymer.

(a) Oligomer is formed directly from monomer. Here we can again make a distinction between: (i) oligomerization occurring by the same mechanism as polymerization (ii) oligomerization following a different mechanism. The first kind has been proposed by Rose for the tetramer formation of oxetane $;^{16}$ up to the fourth monomer added, there is no difference between polymerization and tetramer formation. For polymerization the next step is addition of a fifth monomer molecule. If the next step is reaction between the end hydroxy group and the growing chain, a cyclic secondary oxonium salt is formed which leads to tetramer by a proton transfer to another ether function.

A rather clear situation exists in the case of the $\mathrm{N}$-alkylaziridines reported by $\mathrm{Dick}^{32,33}$ where the nucleophilic character of the counter ion decides if dimer or polymer is formed after two reaction steps from the start.

Oligomer formation by a mechanism different from the polymerization mechanism has been proposed by $\mathrm{Kern}^{6}$ for the tetramer formation of a number of epoxides and by $\mathrm{Pasika}^{10}$ for styrene oxide dimer formation, although in the last case the initiation reactions are probably the same. However, in both cases degradation of polymer would be a possible alternative mechanism.

A system in which there exists good evidence that oligomers are formed directly from monomer is that of the cationic polymerization of hexamethylcyclotrisiloxane. ${ }^{38}$ Apart from polymer of molecular weight $10^{5}$, a mixture of all cyclic siloxanes with ringsize from 6 (monomer) up to 48 have been detected using gas chromatography. The important observation was that oligomers with ringsizes $6,12,18,24 \ldots$. etc. were 10 to 100 times more abundant than the others. This strongly indicates that these oligomers are formed directly from monomer since there are no reasons for supposing that the formation of these rings by a "back-biting" mechanism would be especially favored.

(b) Oligomer is formed by degradation of polymer. If we consider ring-opening polymerization as an equilibrium reaction between monomer and polymer, the equilibrium monomer concentration $\left[\mathrm{M}_{\mathrm{e}}\right]$ will be given by

$$
\ln \left[\mathrm{M}_{\mathrm{e}}\right]=\frac{\Delta \mathrm{G}^{\circ}}{\mathrm{RT}}=\frac{\Delta \mathrm{H}^{\circ}}{\mathrm{RT}}-\frac{\Delta \mathrm{S}^{\circ}}{\mathrm{R}}
$$

where $\Delta G^{\circ}$ is the free energy change for the transformation of monomer to polymer. ${ }^{39}$ In an article of 1955 Dainton, Devlin and $\mathrm{Small}^{40}$ have calculated that for the (hypothetical) polymerization of cycloparaffins and their methyl and 1,1-dimethyl derivatives, the free energy of polymerization is negative up to at least cyclo-octane, with the exception of cyclohexanes and substituted cyclopen- 
tanes. In a subsequent article, Small $^{41}$ estimated that the conclusions arrived at for the cycloparaffins will hold, at least qualitatively, for heterocyclic compounds containing $\mathrm{O}$ or NH. Some deviations are expected for the sulfur compounds due to the larger bond distance of $\mathrm{C}-\mathrm{S}$ compared to $\mathrm{C}-\mathrm{C}, \mathrm{C}-\mathrm{O}$ and $\mathrm{C}-\mathrm{N}$. Since then, the values for the enthalpy $\left(\Delta \mathrm{H}^{\circ}\right)$, entropy $\left(\Delta \mathrm{S}^{\circ}\right)$ and free energy of polymerization for a number of ring-opening polymerizations have been determined. ${ }^{42}$ For three- and fourmembered rings, the enthalpy of polymerization is generally around $-20 \mathrm{kcal} \mathrm{mol}^{-1}$ whereas for most unsubstituted five-membered rings it is around $-5 \mathrm{kcal}$ $\mathrm{mol}^{-1}$. The entropy of polymerization is always negative and the observed values generally lay between -10 and $-25 \mathrm{cal} \mathrm{K}^{-1} \mathrm{~mol}^{-1}$.

Consequently, for three- and four-membered monomers, $\Delta \mathrm{G}^{\circ}$ at room temperature will have highly negative values, so that the equilibrium monomer concentration in these polymerizations will be extremely low. For five-membered rings the factor $T \Delta S^{\circ}$ becomes of the same order of magnitude as $\Delta \mathrm{H}^{\circ}$ at room temperature, so that measurable equilibrium monomer concentrations are found. These equilibrium concentrations increase with temperature and at a certain temperature they will reach a value equal to the molar concentration of the pure monomer. Above this temperature, polymerization is thermodynamically impossible and on the contrary, the polymer will depolymerize, provided that a suitable mechanism exists to allow this to happen. For six-membered and some fivemembered rings, $\Delta \mathrm{H}^{\circ}$ for polymerization is close to zero or even slightly positive which means that at normal temperatures, $\Delta \mathrm{G}^{\circ}$ for polymerization will be positive. Conversely, $\Delta \mathrm{G}^{\circ}$ for depolymerization will have the same value but be negative. In other words, these monomers will be formed from the polymer, if a suitable mechanism exists.

All polymers derived from three-membered heterocycles have structures which allow the formation of six-membered rings. Therefore it is thermodynamically feasible that these polymers will degrade, as long as active species which allow these degradations to occur are present in the polymer chains. This explains why polyoxiranes degrade to 1,4-dioxanes, polythiiranes to 1,4-dithianes and poly $(N$-alkylaziridines $)$ to dialkylpiperazines.

Good evidence exists that cationic polymerization of heterocyclic monomers occurs with cyclic onium salts as the active species. Therefore it is reasonable to believe that the degradation reactions also occur via such ions, so that the most plausible reaction path is the classical "back-biting" mechanism (shown in Scheme 5).

In fact the problem with these polymerizations is not so much: "why does degradation occur?" but rather "why do some polymers not degrade?" and also "why do some polymers degrade to other rings than six-membered rings?"

One obvious possible reason why degradation does not occur under polymerization conditions is that the free

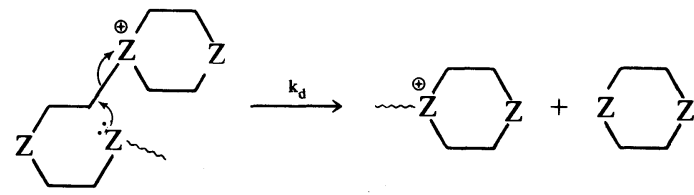

Scheme 5 .

energy of activation for the degradation is too high, i.e. the rate of degradation is too low to observe the phenomenon. This free energy of activation can be influenced by the nature of the solvent and the counter ion, which might explain the different behaviour observed for some monomers when polymerized under different conditions. The presence of substituents on the monomer will certainly play an important role in this connection. However, at the present moment the number of experimental data are insufficient to allow general conclusions to be drawn about the relationship between the nature and the number of substituents and the tendency to degradation.

Degradation of polymer may be absent or occur only to a small extent because of the occurrence of a termination reaction for the degradation. This termination reaction may or may not be the same as the termination reaction for the propagation. For example, the transformation of a three-membered cyclic onium salt to a six-membered cyclic onium salt is a termination reaction for the propagation, but it is the first step of the degradation process. Such a situation is believed to exist in the polymerization of some $N$-substituted aziridines: ${ }^{35}$ polymerization stops at limited conversions but degradation of the polymer to the corresponding piperazine derivative continues after the polymerization has stopped and in the presence of unreacted monomer. Termination of both polymerization and degradation reactions has been observed for the polymerization of propylene sulfide with triethyl oxonium hexachloroantimonate. ${ }^{43}$ The termination in this case is believed to be a reaction between the growing center and the counter ion, forming a chain end which is non-active for further propagation or degradation.

Sometimes oligomers are formed only during the polymerization and when polymerization stops, the formation of the oligomer also ceases. At least three mechanisms can explain this kind of situation:

(i) Polymerization and oligomer formation occur via two independent reaction paths and both reactions stop when monomer is exhausted.

(ii) Propagation and degradation of the polymer occur simultaneously at approximately the same rate. Normally this would lead to oligomer as the only reaction product. However, if a termination reaction prevents the complete degradation of the polymer, the end product will be a mixture of polymer and oligomer.

(iii) Monomer is involved in the mechanism of oligomer formation. This kind of reaction has been proposed for the tetramer formation in the polymerization of oxetanes (Scheme 6):

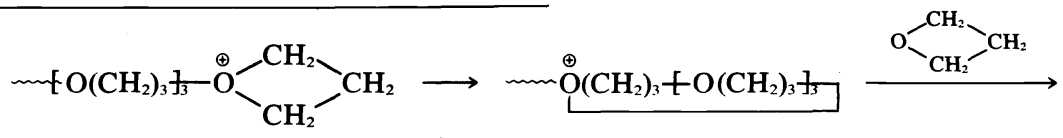$$
\left.m \stackrel{\oplus}{\mathrm{O}}-\mathrm{CH}_{2}-\mathrm{CH}_{2}+\mathrm{CO}\left(\mathrm{CH}_{2}\right)_{3}\right\rceil_{4}
$$ 
After quantitative polymerization, oligomer formation is not possible because of the absence of monomer. Many polymers derived from three-membered heterocycles do not degrade to six-membered rings but to twelve-membered or larger rings. It is possible that the choice between dimer and tetramer is kinetically controlled. The free energy of activation for the formation of a twelve-membered ring could indeed in some cases be smaller than that for the formation of a six-membered ring. In a "back-biting" mechanism the transition state for the formation of a six-membered ring can tentatively be represented as follows:

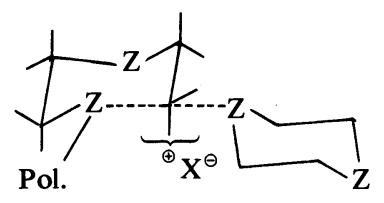

If one or more of the atoms in the ring to be formed carry substituents instead of hydrogen atoms, at least some of these substituents will occur in a gauche butane conformation either to the polymer chain or to the leaving group or/and because they occupy an axial position on the ring. Since each gauche butane interaction increases the enthalpy of activation by $0.8 \mathrm{kcal} \mathrm{mol}^{-1}$, the occurrence or absence of such interactions must have an influence on the rate of oligomer formation. It is expected that this effect is less pronounced when a twelve-membered ring is formed because in that case the ring can adopt such conformations that these gauche butane interactions do not occur. Consequently, the formation of a twelvemembered ring can be kinetically favored.

The importance of the configuration of the recurring units of the polymer chain on the degradation path is nicely demonstrated by comparison of the behaviour of poly-cis-2,3-butylene sulfide and that of poly-trans-2,3butylene sulfide. Both polymers degrade rapidly at room temperature but the degradation products are different. Yet the only difference in the polymer structure is that the recurring units of the polymer derived from the cis-isomer have threo configurations, whereas those of the polymer derived from the trans-isomer have erythro configurations. An analogous observation has been made with propylene sulfide: isotactic poly(propylene sulfide) degrades quantitatively to oligomers, predominantly tetramer, when treated with a catalytic amount of oxonium salt. ${ }^{26}$ Poly(propylene sulfide) obtained by cationic polymerization on the other hand, does not degrade completely. ${ }^{25}$ This might be caused by the presence of a number of head-to-head structures in this polymer. $^{44}$

\section{CONCLUSION}

The formation of cyclic oligomers during or after the cationic polymerization of heterocyclic monomers is a frequently occurring phenomenon. Mostly, the oligomers are formed by degradation of polymer and not directly from monomer. The degradations occur via onium ions which are present in the reaction mixtures because the polymerizations also occur via onium salts. Degradations stop when the active onium salts are destroyed. This can be due to a termination reaction or can be caused by adding a stop reagent.

With a limited number of monomers, oligomers are formed only during the polymerization. This would mean that there exists a termination reaction or that the monomer is involved in the reaction which produces the oligomer. In another number of cases the degradation reaction stops before all polymer is degraded for reasons which are unknown up to now. The ringsize of the cyclic oligomers depends on a number of factors. Steric hindrance, temperature and nature of the counter ion and solvent seem to play an important role in this connection. However, the number of systematic studies in this field is too small to allow the formation of general rules.

The knowledge of the mechanism by which cyclic oligomers are formed during the cationic polymerization of heterocycles is very important in order to allow the experimentator to suppress this reaction or to favor it. If one wishes to produce a polymer, the oligomers are undesirable by-products. On the other hand, it may be interesting from a synthetic point of view to find the experimental conditions which lead to high yields of these oligomers.

Finally, the study of the stereochemistry of the oligomers formed from polymers may help to elucidate the stereochemistry of the polymer and hence give information about the mechanism of polymerization reactions. This applies not only to cationic polymerizations, since a great number of polymers formed by other mechanisms than cationic can be degraded to oligomers when treated with cationic catalysts.

\section{REFERENCES}

'D. J. Worsfold and A. M. Eastham, J. Am. Chem. Soc. 79, 897 (1957).

${ }^{2}$ D. J. Worsfold and A. M. Eastham, J. Am. Chem. Soc. 79, 900 (1957).

${ }^{3}$ G. A. Latremouille, G. T. Merrall and A. M. Eastham, J. Am. Chem. Soc. 82, 120 (1960).

${ }^{4} \mathrm{~J}$. Dale, G. Borgen and K. Daasvatn, Ger. Offen. 2, 401, 126 (1974).

${ }^{s}$ R. J. Katnik and J. Schaefer, J. Org. Chem. 33, 384 (1968).

${ }^{6}$ R. J. Kern, J. Org. Chem. 33, 388 (1968).

${ }^{7}$ R. O. Colclough and K. Wilkinson, J. Polym. Sci. C4, 311 (1966).

${ }^{8}$ R. O. Colclough, G. Oze, W. C. E. Higginson, J. B. Jackson and M. Litt, J. Polymer. Sci. 34, 171 (1959).

${ }^{9}$ S. Kondo and L. P. Blanchard, Polymer Letters 7, 621 (1969). ${ }^{10}$ W. M. Pasika, J. Polym. Sci. A3, 4287 (1965).

${ }^{11}$ A. M. Eastham in: The Chemistry of Cationic Polymerization (edited by P. H. Plesch), Chap. 10, Pergamon Press, New York (1963).

${ }^{12}$ E. J. Vandenberg, J. Polymer. Sci. (A-1) 10, 329 (1972).

${ }^{13}$ K. Weissermel and E. Nolken, Makromol. Chem. 68, 140 (1963).

${ }^{14}$ S. G. Entelis, G. V. Korovina and A. I. Kuzayev, Vysokomol. Soed. A13, 1438 (1971).

${ }^{15}$ Y. I. Estrin and S. G. Entelis, Vysokomol. Soed. A13, 1654 (1971).

${ }^{16} \mathrm{~J}$. B. Rose, J. Chem. Soc. 1956, 542, 546.

${ }^{17}$ Y. Arimatsu, J. Polym. Sci. A1, 728 (1966).

${ }^{18}$ J. M. Andrews and J. A. Semlyen, Polymer 12, 642 (1971).

${ }^{19}$ J. M. Andrews and J. A. Semlyen, Polymer 13, 142 (1972).

${ }^{20}$ T. Miki, T. Higashimura and S. Okamura, Polymer Letters 5, 65 (1967).

${ }^{21}$ S. Okamura, T. Higashimura and T. Miki, Prog. Polymer Sci. Japan 3, 97 (1972).

${ }^{22}$ T. Miki, T. Higashimura and S. Okamura, J. Polym. Sci. (A-1) 5, 2977 (1967).

${ }^{23}$ T. Miki, T. Higashimura and S. Okamura, J. Polym. Sci. (A-1) 5, 95 (1967).

${ }^{24}$ T. Higashimura, A. Tanaka, T. Miki and S. Okamura, J. Polym. Sci. (A-1) 5, 1937 (1967).

${ }^{25}$ P. H. Plesch and P. H. Westermann, Polymer 10, 105 (1969).

${ }^{26} \mathrm{M}$. Okado, S. Kozawa and Y. Yamashita, Makromol. Chem. 127, 271 (1969). 
${ }^{27}$ J. L. Lambert, D. Van Ooteghem and E. J. Goethals, J. Polym. Sci. (A-1) 9, 3055 (1971).

${ }^{28}$ E. J Goethals, D. Van Ooteghem and W. Van Craeynest, Int. Symp. Cationic Polymerization, Rouen, Preprint C-12, September (1973).

${ }^{29}$ W. Van Craeynest and E. J. Goethals, Europ. Polym. J. To be published and unpublished results.

${ }^{30}$ D. Van Ooteghem, R. Deveux and E. J. Goethals, Int. J. Sulfur Chem. 8, 31 (1973).

${ }^{31}$ A. Noshay and C. C. Price, J. Polymer Sci. 54, 533 (1961).

${ }^{32}$ C. R. Dick, J. Org. Chem. 32, 72 (1967).

${ }^{33}$ C. R. Dick, J. Org. Chem. 35, 3950 (1970).

${ }^{34}$ G. R. Hansen and T. E. Burg, J. Heterocycl. Chem. 5, 305 (1968).

${ }^{35}$ E. J. Goethals, E. H. Schacht and P. Bruggeman, Cationic Polymerization, Report C-30, Rouen, September (1973).
${ }^{36} \mathrm{~S}$. Tsuboyama, K. Tsuboyama, I. Higashi and M. Yanagita, Tetrahedron Letters 16, 1367 (1970).

${ }^{37} \mathrm{P}$. Bossaer and E. J. Goethals, Unpublished results.

${ }^{38}$ J. Chojnowski, M. Mazurek, M. Scibiorec and L. Wilczek, Makromol. Chem. 175, 3299 (1974).

${ }^{39}$ F. S. Dainton and K. J. Ivin, Quart. Rev. 12, 61 (1958).

${ }^{40}$ F. S. Dainton, T. R. E. Devlin and P. A. Small, Trans. Faraday Soc. 51, 1710 (1955).

${ }^{41}$ P. A. Small, Trans. Faraday Soc. 51, 1717 (1955).

${ }^{42}$ P. E. M. Allen and C. R. Patrick, Kinetics and Mechanisms of Polymerizations Reactions. p. 211. John Wiley, New York (1974).

${ }^{43}$ E. J. Goethals, Makromol. Chem. 175, 1309 (1974).

${ }^{44}$ S. Boileau, H. Cheradame, N. Spassky, K. Ivin and E. Lillie, C.R. Acad. Sci. (Paris) C275, 535 (1972). 